\title{
ELEVATED TEMPERATURE MECHANICAL BEHAVIOR OF NEW LOW CTE SUPERALLOYS
}

\author{
C.J. Cowen and P.D. Jablonski \\ U.S. Department of Energy National Energy Technology Laboratory 1450 Queen Avenue SW Albany, OR 97321 USA
}

Keywords: Low CTE, Stress Rupture, Phase Stability

\begin{abstract}
This paper presents the high temperature mechanical properties of several experimental low coefficient of thermal expansion (CTE) alloys. The use of such alloys facilitate the extension of advanced ferritic stainless steels to higher use temperature in advanced power generation systems. We find that one of these alloys, J5 appears to be favorable for bridging ferritic alloys (operating up to $\sim 600^{\circ} \mathrm{C}$ ) to traditional nickel based superalloys (operating at $\left.750^{\circ} \mathrm{C}\right)$.
\end{abstract}

\section{Introduction}

The National Energy Technology Laboratory (NETL) is actively involved in efforts to develop the next generation of advanced power turbines in order to provide the United States with secure electric power production capacity which is clean, efficient, affordable, and adaptable to $\mathrm{CO}_{2}$ capture [1]. Such systems are complex and expensive; therefore a systems approach is used to reduce costs whereby the use of low cost materials is maximized whenever possible. From a performance standpoint, the focus has been on developing new materials that can withstand the higher operating pressures and temperatures that will be required in order to increase the efficiency of the next generation of advanced turbines. Alternatively fueled turbine designs such as the Syngas turbine (2010) and the Hydrogen turbine (2015-2020) have turbine inlet temperatures that can be accommodated by thermal barrier coated advanced single crystal nickel based alloys (1370$1425^{\circ} \mathrm{C}$ turbine inlet temperatures and $1015-1115^{\circ} \mathrm{C}$ metal temperatures) [2,3]. However, the advanced Oxy-Fuel turbine design (2015-2020) has inlet temperatures too great for thermal barrier coated nickel based alloys $\left(1760^{\circ} \mathrm{C}\right.$ turbine inlet temperature and $1440^{\circ} \mathrm{C}$ metal temperature) [2-4]. Clearly, this higher inlet temperature will require new alloy development since it is above the melting temperature of essentially all Ni-based superalloys. Regardless of the turbine inlet temperature though, many turbine components will be operating at lower temperatures. The use of new high strength ferritic steels in low to moderate temperature areas, similar to more traditional steam turbine applications, will clearly help achieve system cost-effectiveness $[5,6]$. However, because of the higher system operating temperature, traditional and advanced nickel based superalloys will need to be employed. Attaching nickel alloys to ferritic stainless steels to extend the operating temperature can impose additional stresses on the ferritic component due to the larger coefficient of thermal expansion (CTE) of nickel alloys. This additional stress is exaggerated as the component size increases such as with land based power generation components. The highest additional stress is imposed upon the ferritic component at temperature thus limiting the upper use temperature (and economics) of the ferritic components. However, if a low CTE nickel alloy is used as a bridging element between the ferritic component and the traditional nickel based superalloy the full cost advantage of the ferritic materials can be achieved. More conventional Ni-based superalloys, such as Haynes 230, IN625, or IN725, have CTE values (from Room Temperature (RT) to $700^{\circ} \mathrm{C}$ ) on the order of $14-15 \mathrm{~mm} / \mathrm{mm} /{ }^{\circ} \mathrm{C}$. The commercially available low CTE alloy Haynes 242 displays a CTE of about 12.4 $\mathrm{mm} / \mathrm{mm} /{ }^{\circ} \mathrm{C}$, while the experimental alloys developed at NETLAlbany display values around $12.6 \mathrm{~mm} / \mathrm{mm} /{ }^{\circ} \mathrm{C}$. Various studies on the CTE of Ni-alloys, revealed that $\mathrm{Mn}, \mathrm{Fe}, \mathrm{Co}$ and $\mathrm{Cr}$ increase, while Mo, W, C, Al, and Ti decrease the CTE of Ni [713]. It should be mentioned that $\mathrm{Fe}$ and Co can reduce the CTE if the alloy can remain ferromagnetic. However, above the Currie temperature the material has a higher CTE. Efforts to take advantage of this effect have led to Fe-Ni-Co alloys such as IN903 (which is technically an Fe based alloy). Such alloys suffer from Stress Accelerated Grain Boundary Oxidation (SAGBO) due to the lack of oxidation resistance. Of the elements that increase the CTE for Ni-based alloys, $\mathrm{Cr}$ is most problematic since it is required for environmental integrity. This paper discusses the development and performance of a new series of low coefficient of thermal expansion (CTE) nickel-based superalloys, designated the $\mathrm{J}$-series which are designed to operate as a bridging component in the temperature range of $600-750^{\circ} \mathrm{C}$. The microstructure and mechanical properties determined for experimental alloys J5, J15, and J16 are presented in this paper which provides an initial assessment for their use as a turbine material for energy generation. The excellent oxidation resistance of alloy J5 was reported on earlier; the surface treated version of our alloy exhibits superior oxidation resistance to alloy Haynes 242, and displays the same specific mass gain as alloy Haynes 230 in moist air at $800^{\circ} \mathrm{C}$ [14].

\section{Experimental}

The experimental alloys discussed in this work were designed with the premise of minimizing the coefficient of thermal expansion based on equation (1) from Yamamoto et al [12,13] for iron free, nickel based alloys.

$$
\begin{gathered}
\mathrm{CTE}=13.8732+7.2764 \times 10^{-2}[\mathrm{Cr}]+3.751 \times 10^{-2}([\mathrm{Ta}]+1.95[\mathrm{Nb}]) \\
+1.9774 \times 10^{-2}[\mathrm{Co}]+7.3 \times 10^{-5}[\mathrm{Co}]^{2}+1.835 \times 10^{-2}[\mathrm{Al}] \\
-7.9532 \times 10^{-2}[\mathrm{~W}]-8.2385 \times 10^{-2}[\mathrm{Mo}]-1.63381 \times 10^{-1}[\mathrm{Ti}]
\end{gathered}
$$

The bracketed terms in this equation represent the concentration of each element in the alloy (in weight percent). This equation predicts the mean CTE from room temperature to $700^{\circ} \mathrm{C}$. The computational thermodynamics software Thermo-Calc was utilized to predict the equilibrium phases and to evaluate the effect 
of changes in nominal alloy composition on the predicted phases. After simulation and formulation, the alloys were produced by Vacuum Induction Melting (VIM) high purity elemental materials followed by casting into cylindrical ingots yielding a product approximately $5 \mathrm{~kg}$ in weight and $75 \mathrm{~mm}$ in diameter. After casting the ingots were given a homogenization anneal in a vacuum furnace for 12 hours at $1150^{\circ} \mathrm{C}$. Ingot chemistry was verified through X-ray fluorescence with a Rigaku ZSX Primus II for major constituents, LECO CS244 for carbon/sulfur, and Inductively Coupled Plasma analysis for yttrium (all analyzed using standards). The ingots were fabricated into plate through hot-forging and hot-rolling at $1070^{\circ} \mathrm{C}$ to a thickness of approximately $10 \mathrm{~mm}$. After fabrication, the plates were given a final anneal at $1070^{\circ} \mathrm{C}$, and removed from the furnace to air-cool.

Samples for microstructural evaluation and mechanical property testing were machined from the plate. The microstructure was evaluated by optical microscopy and Scanning Electron Microscopy (SEM) viewed in longitudinal orientation. X-ray Diffraction (XRD) analysis was performed in order to determine the types of phases present in the alloys. Transmission electron microscopy (TEM) studies are ongoing, in order to verify crystal structures, gain insight into local phase chemistries, and to observe post-deformation dislocation structures.

Conventional Vicker's Hardness testing and hot hardness testing $\left(500-1000^{\circ} \mathrm{C}\right)$ were both performed using a $1 \mathrm{~kg}$ load (reported values are the average of 3 readings). Tensile tests were performed at RT and also over the temperature range of 400$800^{\circ} \mathrm{C}$. Stress rupture testing was performed over the stress range of $138-794 \mathrm{MPa}$ and the temperature range of $650-750^{\circ} \mathrm{C}$ at Howmet, Inc. (Whitehall, MI).

\section{Results and Discussion}

The nominal and measured chemical composition of alloys J5, J15, and J16 are presented in Table I.

Table I: Nominal/design [measured] compositions for alloys J5, $\mathrm{J} 15$, and $\mathrm{J} 16$ (values are given in weight percent).

\begin{tabular}{cccccccccc}
\hline Alloy & $\mathrm{Ni}$ & $\mathrm{Cr}$ & $\mathrm{Mo}$ & $\mathrm{W}$ & $\mathrm{Ti}$ & $\mathrm{Mn}$ & $\mathrm{Al}$ & $\mathrm{Y}$ & $\mathrm{C}$ \\
\hline \multirow{2}{*}{$\mathrm{J} 5$} & $\mathrm{Bal}$ & 12.5 & 22.5 & - & 1 & 0.5 & 0.1 & 0.1 & 0 \\
& & {$[12.3]$} & {$[22.0]$} & & {$[1]$} & {$[0.5]$} & {$[0.1]$} & {$[0.08]$} & {$[0.01]$} \\
$\mathrm{J} 15$ & $\mathrm{Bal}$ & 12.5 & 17.5 & 5 & 1 & 0.5 & 0.1 & 0.1 & 0 \\
& & {$[12.3]$} & {$[17.3]$} & {$[4.8]$} & {$[1]$} & {$[0.5]$} & {$[0.1]$} & {$[0.08]$} & {$[0.005]$} \\
$\mathrm{J} 16$ & Bal & 12.5 & 15.5 & 7 & 1 & 0.5 & 0.1 & 0.1 & 0 \\
& & {$[12.2]$} & {$[15.5]$} & {$[6.6]$} & {$[1]$} & {$[0.5]$} & {$[0.1]$} & {$[0.07]$} & {$[0.008]$} \\
Haynes & Bal & 8 & 25 & - & - & 0.5 & - & - & - \\
242 & & & & & & & & & \\
\hline
\end{tabular}

Thermo-calc was used to predict the equilibrium phases in the Jseries alloys. Figure 1 displays plots of weight fraction of phase versus temperature for the three alloys studied; note that the matrix phase in all three alloys is FCC, and this phase comprises the majority of the alloy microstructures, but is not shown in Figure 1. Increasing the $\mathrm{W}$ content of the alloys is predicted to decrease $\mu$-phase stability and increase p-phase stability.

The effect of heat treatment on microstructure was evaluated by solution treating wrought samples of each experimental alloy at $1200^{\circ} \mathrm{C}$ for $10-30$ minutes followed by water quenching, then aging separate samples at $650^{\circ} \mathrm{C}$ or $750^{\circ} \mathrm{C}$ for $2,4,6,24$, or 200 hours. The aging temperatures were chosen based on the phase fields predicted using Thermo-Calc software. After both solutionizing and quenching and solutionizing, quenching and aging, all microstructures retained an average equiaxed grain size of approximately $125 \mu \mathrm{m}$. Figure 2 shows representative SEM micrographs that illustrate the difference between the solution treated (ST) and ST+aged microstructures for the three alloys.
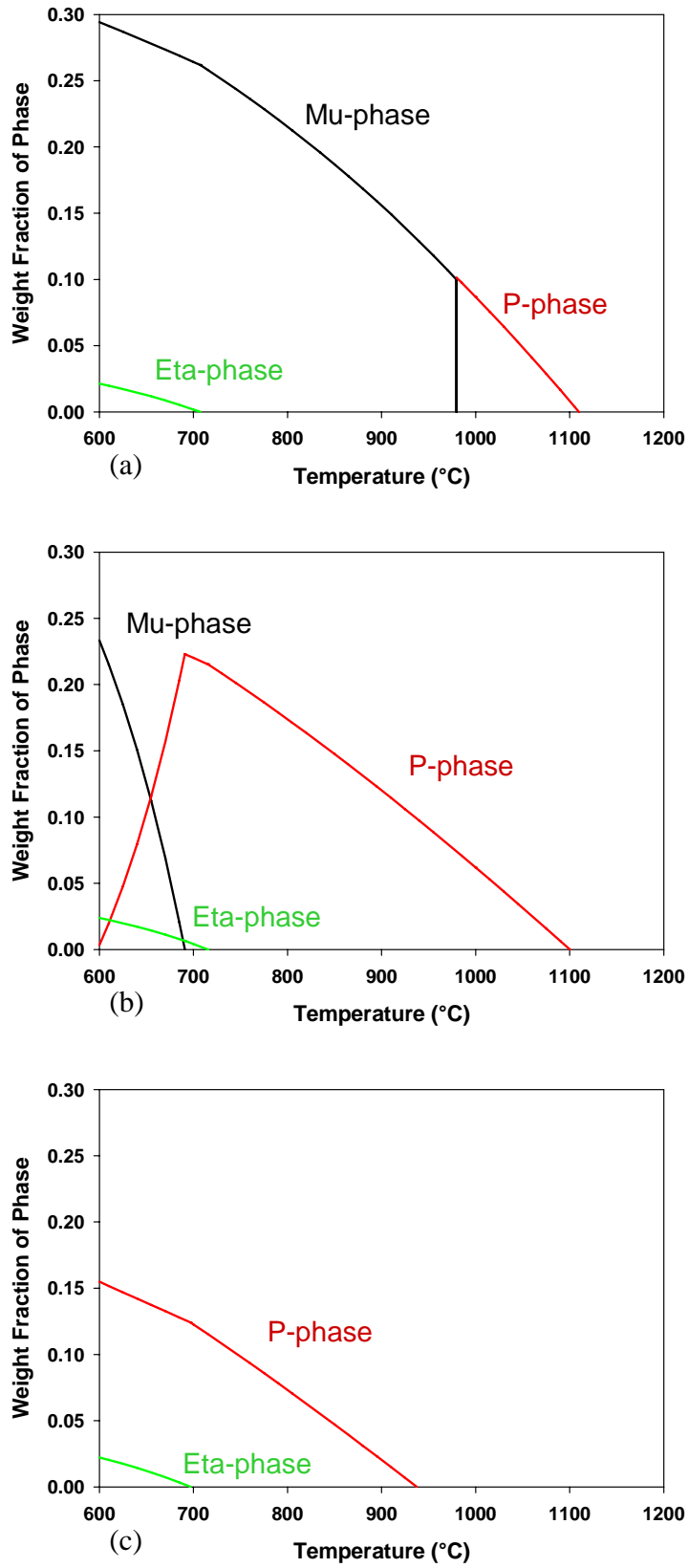

Figure 1. The weight fraction of phase versus temperature predicted by Thermo-calc for: (a) alloy J5, (b) alloy J15, and (c) alloy J16. Note that increasing the nominal alloy tungsten content is predicted to substantially decrease the $\mu$-phase stability. 


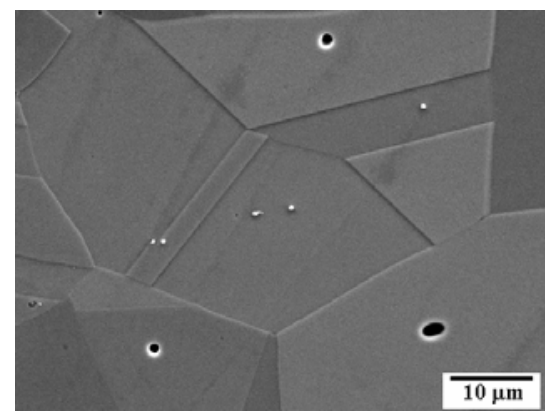

(a)

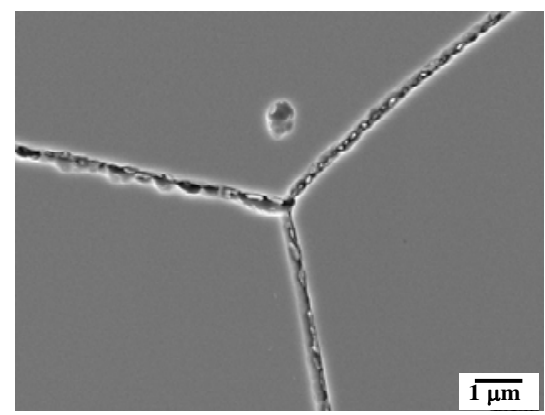

(d)

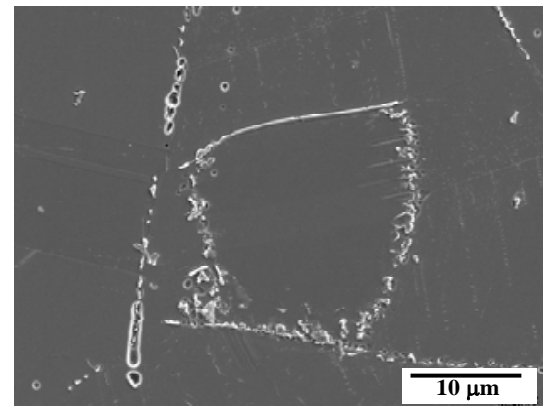

(g)

After aging, a small volume fraction of fragmented second phase particles discontinuously precipitated along the equiaxed FCC grain boundaries. The size and volume fraction of the grain boundary secondary phase was a function of aging time and temperature, and also displayed a dependence on alloy composition. Increasing the aging temperature increased the volume fraction and increasing the aging time increased the size and degree of connectivity of this phase. Previous research performed on the Haynes 242 alloy (which is related to these experimental alloys in its high Mo, low $\mathrm{Cr}$ content) found a similar type of grain boundary phase present when the alloy was subjected to an intermediate heat treatment between $760-980^{\circ} \mathrm{C}$ after solution treatment but prior to aging at $650^{\circ} \mathrm{C}$ for 72 hours [19]. XRD analysis coupled with EDS analysis performed on TEM samples led the authors to conclude that this grain boundary phase was the topologically close-packed (TCP) hexagonal $\mu$ phase, with a Mo content ranging from 50 to $65 \%$. Due to the similarity in nominal composition and phase morphologies between alloy $\mathrm{J} 5$ and Haynes 242, in addition to the fact that Mo is known to be a $\mu$-phase stabilizer [15-17], the grain boundary phase present in the $\mathrm{J}$ alloys is suggested to be the $\mu$-phase.
A large volume fraction of intragranular second phase, suggested to be $\mathrm{Ni}_{2}(\mathrm{Mo}, \mathrm{Cr})$-based with the $\mathrm{Pt}_{2} \mathrm{Mo}$ ordered orthorhombic structure [22] is present in alloy $\mathrm{J} 5$ after aging at $750^{\circ} \mathrm{C}$, but is not present to the same degree in alloys J15 and J16 after aging (see Figure 2). This crystal structure is suggested based on similarity in composition and morphology to that found in $\mathrm{Ni}-\mathrm{Mo}-\mathrm{Cr}$ alloys of similar composition [18-21]. TEM work is ongoing in verifying the crystal structure. $\mathrm{Ni}_{2}(\mathrm{Mo}, \mathrm{Cr})$ would be the expected equilibrium phase because $\mathrm{Cr}$ atoms have been shown to substitute for Mo atoms in this crystal structure [18,22], Cr and $\mathrm{Mo}$ are in the same group in the periodic table, $\mathrm{Ni}_{2} \mathrm{Cr}$ is an equilibrium phase in the $\mathrm{Ni}-\mathrm{Cr}$ binary phase diagram [24], and due to the fact that $\mathrm{Ni}_{2} \mathrm{Cr}$ and $\mathrm{Ni}_{2} \mathrm{Mo}$ posses $\mathrm{Pt}_{2} \mathrm{Mo}$-type crystal structures [19]. The XRD results for alloys J5, J15, and J16 are presented in Figure 3. It is clear that coherency strains, likely due to ordering, have arisen in the J5 ST+aged microstructure when one compares the larger widths of the FCC matrix reflections in this pattern to the smaller widths of the matrix reflections obtained from the J5 ST microstructure. The peak widths of the FCC matrix reflections were also observed to be directly proportional to the Mo content of the alloy. That is, the width of the J5 reflections are greater than the J15 reflections, which are greater 
than the J16 reflections; these results correlate well with the fact that the $\mathrm{Ni}_{2}(\mathrm{Mo}, \mathrm{Cr})$ phase was absent from the grain interiors in the SEM images of alloys J15 and J16 presented in Figure 2. The $\mathrm{Ni}_{2}(\mathrm{Mo}, \mathrm{Cr})$ phase (or possibly either the p-phase or eta-phase) may be present in alloys $\mathrm{J} 15$ and $\mathrm{J} 16$, but was only observed in the immediate vicinity of the equiaxed FCC grain boundaries of these alloys. This phase shows evidence of precipitating first from the parent equiaxed FCC grain boundaries by a Widmanstatten mechanism. In alloy $\mathrm{J} 5$ this phase precipitates first from the equiaxed FCC grain boundaries, and proceeds to grow and occupy a majority of the grain interiors. Growth into intragranular regions did not occur in alloys $\mathrm{J} 15$ and $\mathrm{J} 16$, and in fact halted within the immediate vicinity of the equiaxed FCC grain boundaries. This phenomenon can be explained by the difference in nominal alloy chemistry, in particular the Mo to $\mathrm{W}$ ratio; alloy $\mathrm{J} 5$ contains no $\mathrm{W}$, and the Mo to $\mathrm{W}$ ratio (in atomic percent) is 6.7 and 4.3 in alloys $\mathrm{J} 15$ and J16, respectively. It is apparent that this phase nucleates at the grain boundaries, and then growth proceeds along specific crystallographic planes into the grain interiors. In order for this to occur, Mo must be consumed from the austenitic matrix phase in order for the precipitating phase to grow. With 22 wt\% Mo available in alloy J5, this growth can easily progress into the grain interiors. With the lower amount of Mo available in alloys J15 and J16, it appears possible to nucleate this phase at the grain boundaries (where an excess of Mo could be expected to segregate), however it is proposed that the growth cannot continue into the grain interiors due to the lack of an available supply of Mo needed for this phase to grow.

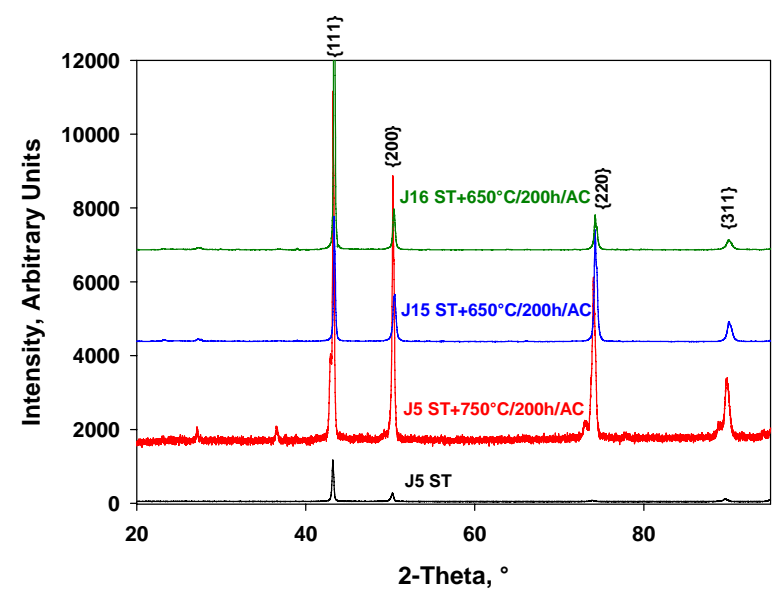

Figure 3. XRD spectrums obtained alloys J5, J15, and J16.

Tensile properties were determined as a function of temperature and were used to choose appropriate temperatures and stress levels to perform stress rupture and creep tests. Figure 4 shows the temperature dependence of the yield strength and compares the yield strength of the J-series to that of Haynes 242 hot rolled plate that has been annealed and aged [23]. The yield strength of alloy J5 ranges from about 450 to about $500 \mathrm{MPa}$ in the 550$750^{\circ} \mathrm{C}$ range while the yield strength for Haynes 242 varies from about 600 to about $500 \mathrm{MPa}$ over the same range.

Figure 5 shows the Vicker's Hardness of the alloys as a function of temperature. The hardness data correlates well with the tensile data for alloy $\mathrm{J} 5$, in that both the yield strength and the hardness increase over the temperature range of $550-700^{\circ} \mathrm{C}$. This phenomenon provides an indication of strengthening due to the thermally activated cross-slip and subsequent locking of superdislocations on low-index planes within an intermetallic second phase. In alloy $\mathrm{J} 5$, this must be attributed to the large volume fraction of $\mathrm{Ni}_{2}(\mathrm{Mo}, \mathrm{Cr})$ phase present within the equiaxed FCC grains. The strengthening cannot be attributed to the $\mu$ phase, as this phase was observed to be present in all three alloys, and the hardness and yield strength values of alloys J15 and J16 show the trend of continuously decreasing as temperature increases. In addition, strengthening would not be expected to arise from the presence of the $\mu$-phase based upon it solely being located at the grain boundaries; due to it's location and fragmented morphology, this phase would be expected to have more of an influence on the creep deformation behavior, in particular how it affects the contiguity of the FCC grain boundaries.

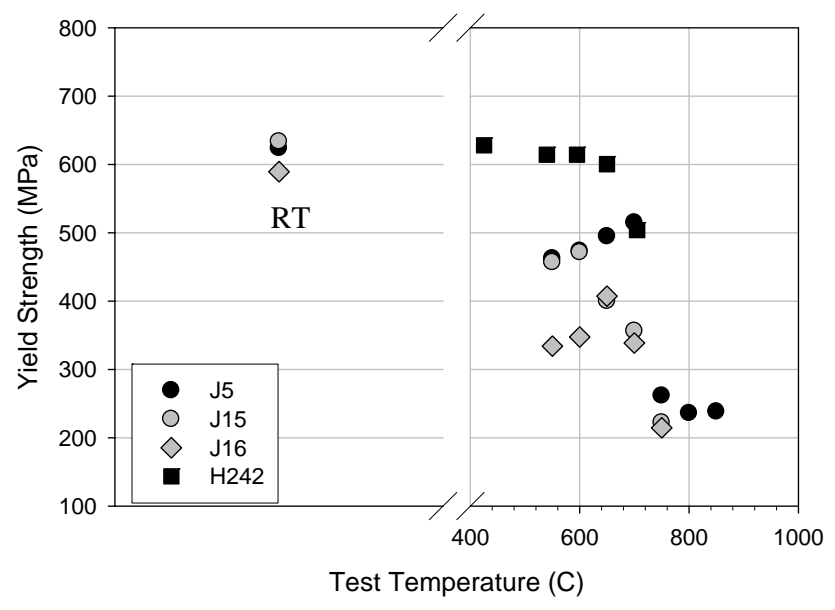

Figure 4. Yield strength versus temperature.

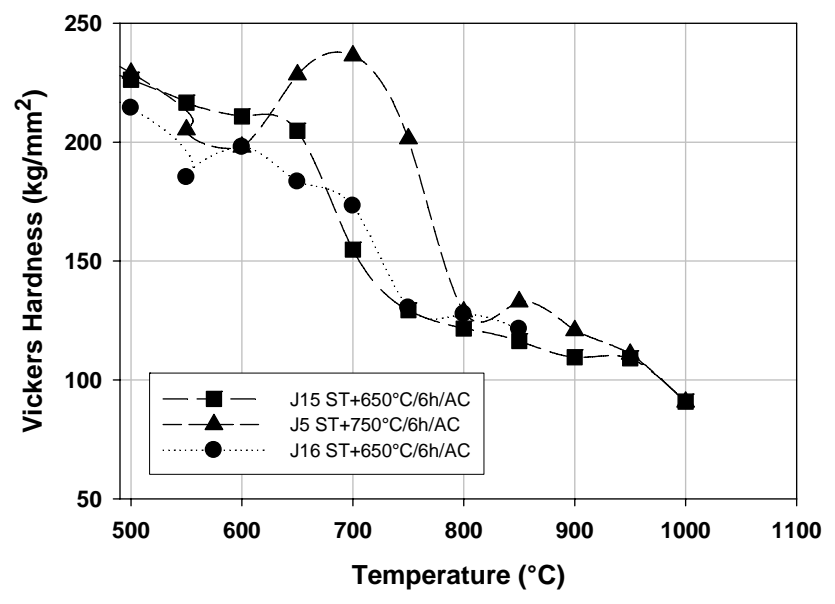

Figure 5. Vicker’s Hardness versus temperature. 
The alloy $\mathrm{J} 5 \mathrm{ST}+750^{\circ} \mathrm{C} / 6 \mathrm{~h} / \mathrm{AC}$ microstructure was chosen as the main focus for stress rupture testing based upon its strength retention, $\mathrm{Ni}_{2}(\mathrm{Mo}, \mathrm{Cr})$ phase volume fraction, microstructural stability, and the ultimate target of a $760^{\circ} \mathrm{C}$ application temperature. Figure 6 shows a plot of stress versus Larson-Miller Parameter for alloy J5 and Haynes 242. For the stress and temperature range examined alloy J5 clearly displays a stress rupture life superior to that of Haynes 242. Figure 7 shows results from stress rupture testing at $650^{\circ} \mathrm{C}$ for alloys J5, J15, J16, and Haynes 242. At $650^{\circ} \mathrm{C}$, Haynes 242 and alloy J5 exhibit lifetimes roughly the same order of magnitude, however at this temperature Haynes 242 out performs alloy J5. For stresses greater than 450 $\mathrm{MPa}$, the creep rupture lifetimes of alloys J15 and J16 decrease catastrophically. From a microstructural stand point, alloys J5, $\mathrm{J} 15$, and $\mathrm{J} 16$ have essentially the same equiaxed FCC grain size $(\sim 125 \mu \mathrm{m})$ and $\mu$-phase volume fraction. The key difference is the lack of the ordered $\mathrm{Ni}_{2}(\mathrm{Mo}, \mathrm{Cr})$ phase in alloys $\mathrm{J} 15$ and $\mathrm{J} 16$. The secondary phase present in alloys J15 and J16 (which could potentially be the eta-phase, p-phase, or the $\mathrm{Ni}_{2}(\mathrm{Mo}, \mathrm{Cr})$ phase) was only observed within the immediate vicinity of the equiaxed FCC grain boundaries, which is suggested to be due to lack of enough Mo to stabilize this phase throughout the microstructures; this is due to the addition of $\mathrm{W}$ to alloys $\mathrm{J} 15$ and $\mathrm{J} 16$ in exchange for Mo. While $\mathrm{W}$ is well known as a solid-solution strengthener of the austenitic matrix, the poor rupture lives displayed by alloys J15 and J16 illustrate the superiority and need for ordered intermetallic reinforcement of the matrix in order for the superalloy to have adequate creep rupture resistance.

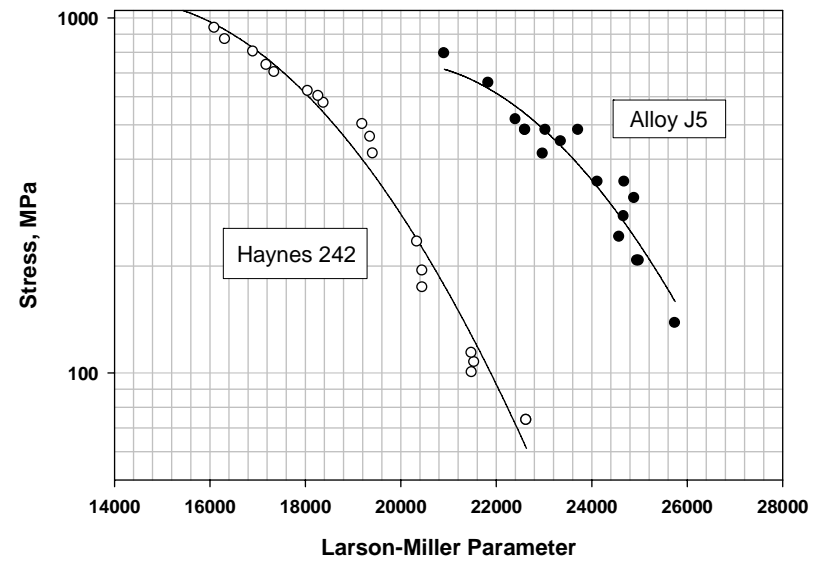

Figure 6. Stress versus Larson-Miller Parameter comparison for alloy J5 and Haynes 242.

Figure 8 shows results from stress rupture testing at $750^{\circ} \mathrm{C}$ for alloy J5 compared to that of Haynes 242 tested at $760^{\circ} \mathrm{C}$. Once again, under comparable test conditions both Haynes 242 and alloy $\mathrm{J} 5$ show comparable lifetimes, however at this temperature alloy J5 out performs Haynes 242. Although the data is limited, it is interesting to note that at this higher temperature, these two alloys do not appear to have the same stress-life dependence and that perhaps the Haynes 242 alloy may have longer life at lower stress.

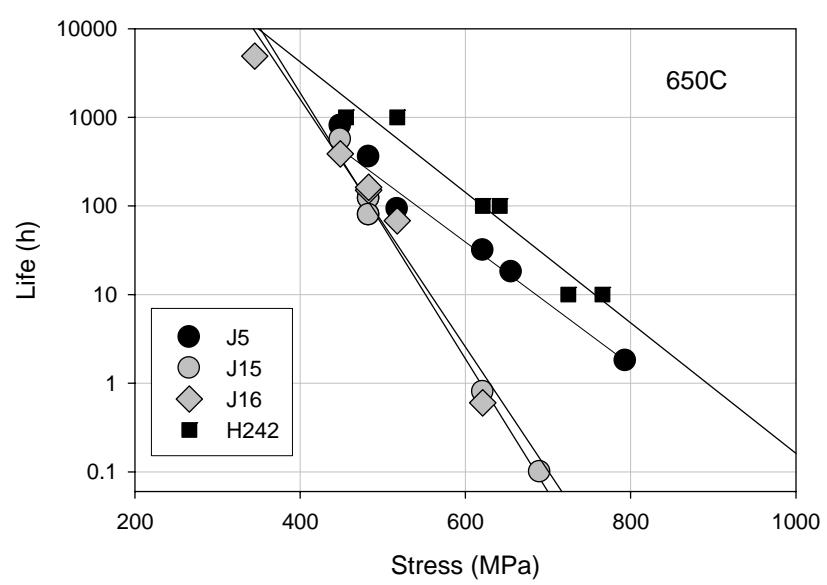

Figure 7. Creep rupture life versus stress for alloys J5, J15, J16, and for Haynes 242 obtained at $650^{\circ} \mathrm{C}$.

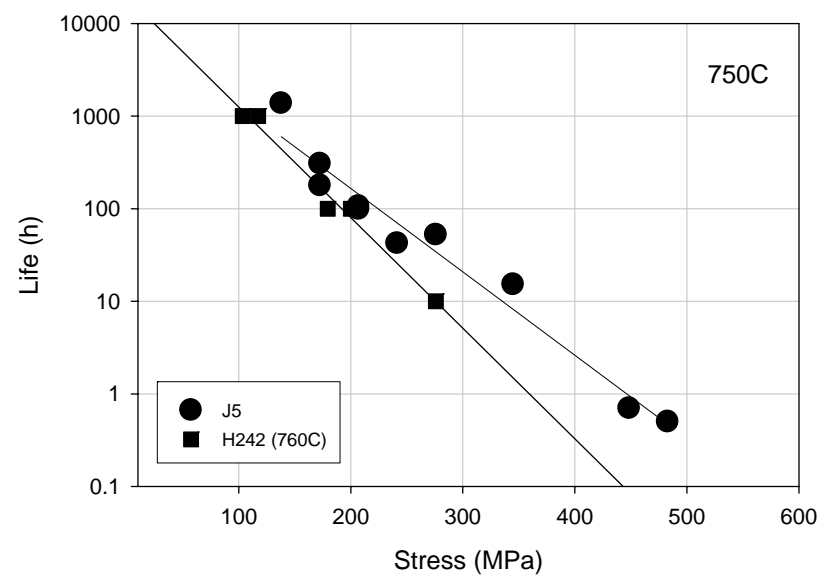

Figure 8. Creep rupture life versus stress for alloys J5 obtained at $750^{\circ} \mathrm{C}$ and Haynes 242 obtained at $760^{\circ} \mathrm{C}$.

Figure 9 shows electron micrographs obtained from alloy J5 samples stress rupture tested under conditions of $207 \mathrm{MPa} / 750^{\circ} \mathrm{C}$; one sample was aged at $650^{\circ} \mathrm{C}$ for 6 hours prior to testing and another sample was aged at $750^{\circ} \mathrm{C}$ for 6 hours. The samples failed after 93.9 and 98.9 hours in the $650^{\circ} \mathrm{C} / 6 \mathrm{~h} / \mathrm{AC}$ and $750^{\circ} \mathrm{C} / 6 \mathrm{~h} / \mathrm{AC}$ aged conditions, respectively. Cracking of grain boundaries located perpendicular to the tension axis was the form of creep damage observed from within the bulk of the postmortem samples. The initial creep testing performed (not discussed within this work) has resulted in creep stress exponent values much larger than 2 . Therefore, the grain boundary cracking observed within the bulk is thought to be due to the sliding of the equiaxed FCC grain boundaries as an accommodation process to an intragranular diffusion-assisted dislocation process such as solute drag limited glide or dislocation climb. Grain boundary sliding is not believed to be a dominant secondary creep mechanism in alloy J5. 

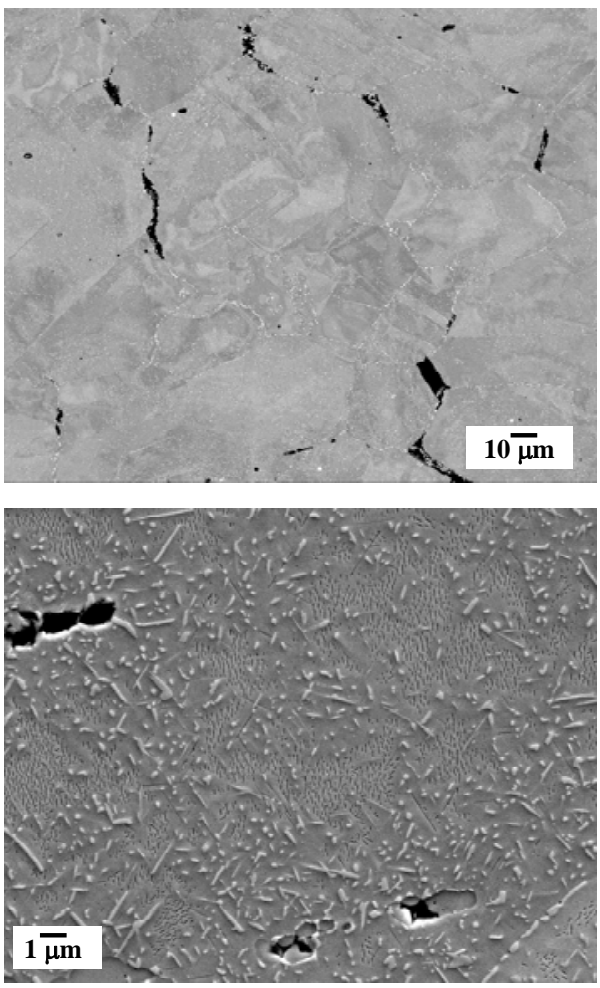

(b)

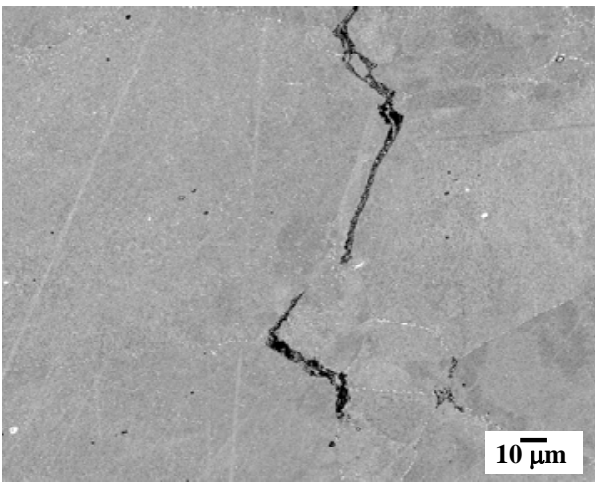

(d)

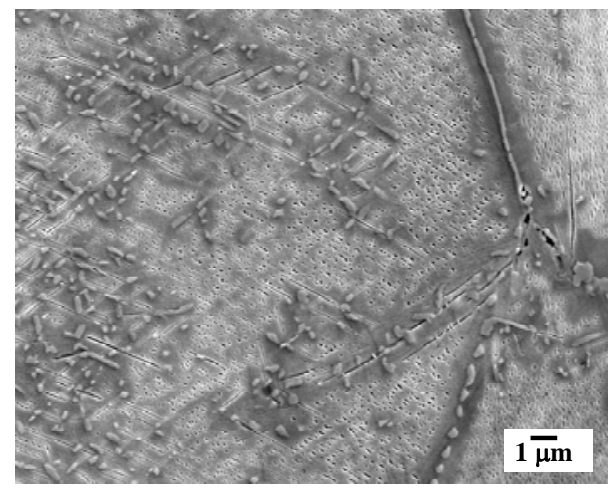

Figure 9. Electron micrographs of alloy J5 samples stressrupture tested under conditions of $207 \mathrm{MPa} / 750^{\circ} \mathrm{C}$. The sample shown in micrographs (a) and (b) was aged at $650^{\circ} \mathrm{C}$ for 6 hours prior to testing and the sample shown in micrographs (c) and (d) was aged at $750^{\circ} \mathrm{C}$ for 6 hours prior to testing.
The microstructures presented in Figure 9 provide insight into the microstructural evolution that occurs in alloy J5, and these insights are illustrated by directly comparing the differences in the microstructures presented in Figure 2 (directly aged) to those in Figure 9 (aged and stress rupture tested). After 200 hours of aging at $650^{\circ} \mathrm{C}$, no intragranular second phases were observed in alloy J5; in fact, only small volume fractions of the $\mu$-phase were observed at the equiaxed FCC grain boundaries. In stark comparison to this, the sample aged at $650^{\circ} \mathrm{C}$ for 6 hours followed by stress rupture testing contains a large volume fraction of additional intragranular secondary phases. One of these phases posses the same morphology as that of the $\mathrm{Ni}_{2}(\mathrm{Mo}, \mathrm{Cr})$ phase only observed in $\mathrm{J} 5$ samples aged at $750^{\circ} \mathrm{C}$. The other phase possesses a plate-like morphology representative of either the TCP eta or pphase [15-17]. This phase is suggested to be the eta-phase and not the p-phase based upon Thermo-Calc predictions (See Figure 1 (a)). The main microstructural difference observed between the post stress rupture tested samples and the directly aged samples was the presence of a large volume fraction of $\mu$-phase throughout the grain interiors. The $\mu$-phase was never observed within the grain interiors of the directly aged samples, which leads to the conclusion that the intragranular precipitation of this phase is both stress and temperature dependent. Denuded zones surround the $\mu$ phase precipitates located at both the grain boundaries and within the grain interiors, which is most typically due to Mo being scavenged from, and hence weakening, the surrounding FCC matrix. The denuded zones are also devoid of the phase suggested to be $\mathrm{Ni}_{2}(\mathrm{Mo}, \mathrm{Cr})$, which would also imply the denuded zones found around the $\mu$-phase particles are Mo deficient.

\section{Conclusions}

The high temperature mechanical properties and the microstructural development of new experimental alloys have been presented. The thermodynamic modeling software, ThermoCalc, was successfully used in their design. One of the alloys, J5, has been shown to have comparable high temperature strength and stress rupture properties to the commercial low CTE alloy Haynes 242. The advantage of alloy J5 over Haynes 242 is the $1.5 \mathrm{x} \mathrm{Cr}$ level of this experimental alloy. The remaining experimental alloys, J15 and J16 showed poor high temperature mechanical performance. The favorable long term oxidation resistance, high temperature strength, and creep rupture properties of alloy J5 have been shown here and in previous work [14]; therefore, continued interest in this alloy for use as a bridging component between lower cost ferritic materials and higher cost Ni-based superalloys is anticipated. Under certain applications, the fatigue resistance (especially at high temperature and/or due to thermal stresses) will be the life limiting material characteristic of these bridging components. The development of this series of low CTE alloys will help minimize thermal fatigue effects, and the planning of fatigue testing of these new alloys is currently underway.

\section{Acknowledgements}

This worked was performed while one of the authors (CJC) held a National Research Council Postdoctoral Research Associateship from the National Academy of Sciences. Both authors would like to thank the following NETL-Albany staff members for their contributions to this work: E. Argetsinger (melting and fabrication), M. Arnold (XRF), J. Robbins (ICP), C. Williamson (Carbon/Sulfur), D. Smith (XRD), K. Collins (SEM), P. Danielson (metallography). 


\section{References}

1. Report to Congress, "FutureGen Integrated Hydrogen, Electric Power Production and Carbon Sequestration Research Initiative," U.S. DOE, Office of Fossil Energy, March 2004.

2. Available at: http://www.netl.doe.gov/publications/factsheets/rd/R\& D041.pdf

3. Available at: http://www.netl.doe.gov/publications/factsheets/rd/R\& $\underline{\text { D103.pdf }}$

4. B.A. Pint, J.R. DiStefano, I.G. Wright, Materials Science and Engineering A 415 (2006) 255-263.

5. R. Viswanathan, A.F. Armor and G. Booras, Proc. Of International Conf. on Thermal Power Generation, organized by NTPC/USAID, New Delhi, Oct. 13-15, 2003, V2, p23-43.

6. R. Viswanathan, A.F. Armor and G. Booras, Power, April, 2004, p42.

7. D.R. Muzyka, C.R. Whitney, D.K. Schlosser, JOM, vol 11, July, 1975, p.11.

8. S.K. Hwang, F.C. Hull, J.M. Wells, in Superalloys1984, TMS, Warrendale, PA, p. 785.

9. J.M. Wells, S.K. Hwang and F.C. Hull, in Refractory Alloying Elements in Superalloys, ASM, Materials Park, OH, 1984, p. 175.

10. H. Morrow, D.L. Sponseller , M. Semchyhsen, Metall. Trans. A, 6A, 1975, p. 477.

11. P.K. Sung, D.R. Poirier, Mat. Sci. Engr. A245, 1998, p. 135.

12. R. Yamamoto, Y, Kadoya, H. Kawai, R. Magoshi, T. Noda, S. Hamano, S. Ueta, S. Isobe, , in Materials for Advanced Power Engineering -2002, Proc. 7th Leige Conf. Sept 30-Oct 3, 2002, Energy and Technology Vol 21., Forschungszentium Julich Gmbh Inst. Fur Werkstoffe und Verfahren der Energietechnik.
13. R. Yamamoto, Y, Kadoya, S. Ueta, T. Noda, R. Magoshi, S. Nishimoto, T. Nakano, Proc. From the $4^{\text {th }}$ International Conf on Adv. In Mat. Tech. for Fossil Power Plants, Oct. 25-28, 2004, p623.

14. D.E. Alman and P.D. Jablonski, Superalloys 2004, K.A Green, T.M Pollock, H. Harada, T.E. Howson, R.C. Reed, J.J. Schirra and W. Walston Ed., TMS Warrendale, PA, p617.

15. C. T. Sims, N. S. Stoloff, W. C. Hagel, ed. John Wiley \& Sons pub. 1987, pp218.

16. M. Raghavan, R.R. Mueller, G.A. Vaughn, and S. Floreen, Met. Trans. A V15A, p783 (1984).

17. E. Gozlan, M. Bamberger, S.F. Dirnfeld, B. Prinz, and J. Klodt, Mat Sci and Eng, A141 (1991) p85.

18. Y.L. Lu, L.M. Pike, C.R. Brooks, P.K. Liaw, and D.L. Karstrom, Scripta Materialia, Vol. 56 pg.121-124 2007.

19. S. Dymek, M. Dollar, and M. Farooqi, Materials Science and Engineerg A vol.319-321 pg.284-289 2001.

20. S. Dymek, M. Wrobel, and M. Dollar, Scripta Materialia vol. 43 pg.343-348 2000.

21. S. Dymek, M. Dollar, and D.L. Klarstrom, Scripta Metallurgica et Materialia, vol 25 pg865-869 1991.

22. Kumar and V.K. Vasudevan, Acta Mater. 44 1591-1600 (1996).

23. Available

at: http://www.haynesintl.com/242site/242tp.htm

24. T.B. Massalski et al., eds., Binary Alloy Phase Diagrams, $2^{\text {nd }}$ ed., vol. 2 (Metals Park, OH: American Society for Metals, 1990), p1298. 